\title{
EFEK WAKTU MILLING TERHADAP KARAKTERISASI PARTIKEL KAPUR ALAM DENGAN MENGGUNAKAN X-RAY DIFFRACTION
}

\section{(EFFECT OF MILLING TIMES FOR CHARACTERIZATION OF NATURAL LIMESTONE PARTICLE USING X-RAY DIFFRACTION)}

\author{
Indra Gunawan ${ }^{1}$, Saeful Yusuf ${ }^{1}$, Sudirman $^{1,2}$ dan Wiwik Pudjiastuti ${ }^{3}$ \\ ${ }^{1}$ Pusat Teknologi Bahan Industri Nuklir - BATAN \\ Kawasan Puspiptek Cisauk Tangerang Selatan 15314 \\ 2Jurusan Kimia, FMIPA - Universitas Indonesia \\ Kampus Baru UI, Depok \\ ${ }^{3}$ Balai Besar Kimia dan Kemasan, Kementerian Perindustrian \\ JI. Balai Kimia No.1 Pekayon, Pasar Rebo, Jakarta Timur \\ E-mail: indrag@batan.go.id
}

Received 4 Maret 2011; revised 11 Maret 2011; accepted 11 April 2011

\begin{abstract}
ABSTRAK
Telah dilakukan karakterisasi partikel kapur alam akibat variasi waktu milling dengan X-Ray Diffraction (XRD). Kapur alam yang awalnya digerus dengan mortar dan diayak sehingga didapatkan serbuk berukuran 400 mesh. Kapur alam hasil ayakan kemudian digiling dengan High Energy Milling (HEM) pada variasi waktu penggilingan 3 jam, 6 jam, 9 jam, 12 jam, 15 jam, dan 18 jam. Pada setiap selang waktu tersebut dilakukan karakterisasi dengan menggunakan $X R D$. Hasil pola difraksi dipelajari dengan menggunakan pencocokan dengan kartu Hanawalt dan diambil kesimpulan bahwa kapur alam terdiri dari $\mathrm{Ca}(\mathrm{OH})_{2}$ dan $\mathrm{CaCO}_{3}$. Sedangkan ukuran partikel dipelajari dengan mengamati pelebaran pola difraksi menggunakan metode Scherrer. Hasil perhitungan dengan metode Scherrer menghasilkan ukuran partikel $\mathrm{Ca}(\mathrm{OH})_{2}$ menjadi mengecil dari $1125 \mathrm{~nm}$ pada waktu milling 3 jam menjadi $473,7 \mathrm{~nm}$ pada waktu milling 18 jam atau terjadi penurunan ukuran partikel sebesar $57,9 \%$. Sedangkan untuk partikel $\mathrm{CaCO}_{3}$ pengecilan ukuran partikel terjadi dari $9000 \mathrm{~nm}$ pada waktu milling 3 jam menjadi $600 \mathrm{~nm}$ pada waktu milling 18 jam atau terjadi penurunan ukuran partikel sebesar $93,3 \%$.
\end{abstract}

Kata kunci : Kapur alam, Nanopartikel, High Energy Milling (HEM), X-Ray Diffraction (XRD), Metode Scherrer

\begin{abstract}
The characterization of natural limestone due to milling times variation have been done using X-Ray Diffraction $(X R D)$. Starting materials of natural limestone was grinded by mortar and sifted by 400 mesh sieve. The resulting material of this natural limestone then milled using High Energy Milling (HEM) at various milling times of 3, 6, 9, 12, 15 and 18 hours. At the interval time of milling, the sample was taken to be characterized by using XRD. The diffraction pattern was examined and compared with Hanawalt card to identify the phase contents in the materials. The identification shows that the natural limestone contains $\mathrm{Ca}(\mathrm{OH})_{2}$ and $\mathrm{CaCO}_{3}$. However the particles size was studied by broadening peaks inspections and calculations with Scherrer method. The result of the calculation shows that particle size of $\mathrm{Ca}(\mathrm{OH})_{2}$ decreased from $1125 \mathrm{~nm}$ at 3 hours milling to $473.7 \mathrm{~nm}$ at 18 hours milling or there is $57.9 \%$ of decreasing particle size. Meanwhile for $\mathrm{CaCO}_{3}$ particle, there is a decreasing particle size from $9000 \mathrm{~nm}$ at 3 hours milling to $600 \mathrm{~nm}$ at 18 hours milling or the percentage decreasing particle is $93.3 \%$.
\end{abstract}

Key words : Natural limestone, Nanoparticle, High Energy Milling (HEM), X-Ray Diffraction (XRD), Scherrer method

\section{PENDAHULUAN}

Batu kapur dapat terjadi dengan beberapa cara yaitu secara organik, mekanik atau kimia. Sebagian besar batu kapur yang terdapat di alam terjadi secara organik, jenis ini berasal dari pengendapan rumah kerang dan siput, ganggang atau berasal dari kerangka binatang 
koral. Batu kapur dapat berwarna putih susu, abu tua, abu muda, coklat bahkan hitam, tergantung keberadaan mineral pengotornya. Mineral karbonat yang umum ditemukan berasosiasi dengan batu kapur adalah aragonit $\left(\mathrm{CaCO}_{3}\right)$ yang merupakan mineral metastabil karena pada kurun waktu tertentu dapat berubah menjadi kalsit.

Batu kapur banyak digunakan di berbagai industri untuk keperluan tertentu seperti di industri kimia, batu kapur perlu diproses terlebih dahulu dengan cara pembakaran sehingga menjadi kapur tohor ( $\mathrm{CaO}$ ) atau kapur padam $\mathrm{Ca}(\mathrm{OH})_{2}$. Selain itu kapur dapat juga dimanfaatkan untuk dibuat sebagai bahan baku nutrisi ternak yang dikenal dengan kalsium hidrofosfat $\left(\mathrm{CaHPO}_{4}\right)$. Penggunaan batu kapur yang lain adalah untuk bahan campuran bangunan, industri karet dan ban, kertas dan lain-lain.

Di industri polimer batu kapur digunakan sebagai aditif untuk menstabilkan, memodifikasi dan meningkatkan performa polimer. Penambahan aditif atau bahan pengisi seperti $\mathrm{TiO}_{2}$, $\mathrm{SiO}_{2}$, talc, $\mathrm{ZnO}_{2}$ dan $\mathrm{CaCO}_{3}$ ke dalam polimer akan memperbaiki sifat-sifat fisika. Bahan pengisi alam yang sering digunakan adalah kalsium karbonat, karena kelimpahannya di alam. Bahan pengisi ini telah ditambahkan ke dalam matrik polimer seperti: poli vinil klorida, poli propilen, elastomer dan poli ester rantai tak jenuh. Bahan pengisi lain yang juga telah banyak digunakan adalah partikel tanah liat seperti kaolinit dan metakaolin.

Penambahan bahan pengisi dalam ukuran nano telah banyak dilakukan karena pendekatan ini menarik yaitu daerah antar muka (interface) antara bahan pengisi dan matrik dapat mencapai beberapa ratus meter persegi, sehingga menghasilkan peningkatan interaksi antar muka dan sifat material secara makroskopik. Bahan komposit dengan bahan pengisi ukuran nano yang kemudian dinamakan nanokomposit telah banyak dipelajari karena memiliki sifat-sifat gabungan yang tidak umum (Lorenzo 2002; Wan 2003; Chabert 2004).

Sifat-sifat yang nyata berbeda dari bahan dasarnya diperoleh sebagai konsekuensi dari luas muka yang bertambah besar jika digunakan bahan pengisi dari bahan nano (Chen 2004). Bahan pengisi ukuran nano yang digunakan adalah montmorillonite (Wang 2004), silika (Garcia 2004) dan karbonat (Mishra 2005), dimana bahan pengisi ini akan meningkatkan kekuatan, modulus dan keuletan.
Pembuatan partikel nano bisa dilakukan secara fisika maupun kimia. Cara fisika adalah paling mudah dan sederhana yaitu dengan melakukan penggerusan di dalam alat seperti ball mill. Sedangkan cara kimia bisa dilakukan dengan berbagai metode seperti evaporasi gas, presipitasi dan sol-gel.

Milling atau penggilingan adalah suatu proses mekanik untuk menghancurkan suatu bahan dengan alat yang bekerja berputar sehingga ukuran butiran akan semakin kecil. Penggilingan ini dapat menghancurkan struktur mineral dan dihasilkan partikel nano dengan luas muka yang meningkat. Milling merupakan proses mekanik untuk menghancurkan suatu bahan menjadi partikel yang lebih kecil dengan suatu alat yang berputar. Proses milling ini merupakan proses penghalusan secara fisika, kapur alam digerus dengan menggunakan High Energy Milling (HEM) seri 8000 M. Prinsip kerja alat HEM ini adalah menghancurkan suatu bahan atau memperkecil ukuran partikel dengan mencampurnya secara homogen. Bahan ditempatkan dalam wadah yang di dalamnya terdapat bola-bola logam untuk menggiling bahan menjadi lebih kecil. Perbandingan berat antara bahan dengan bola adalah $1: 2$. Perbandingan ini berpengaruh terhadap ukuran partikel yang dihasilkan. Wadah kemudian ditempatkan dalam alat milling dan dijepit dengan kuat. Waktu penggilingan dapat dipilih. Setelah alat dihidupkan wadah tadi akan berputar bolak-balik sehingga bahan dapat tercampur dan bola-bola logam bekerja untuk menghaluskan bahan menjadi lebih halus lagi.

Ball milling telah digunakan oleh industri sejak dahulu untuk melakukan pengurangan ukuran suatu bahan. Sekarang ini bahan dengan struktur mikro dan sifat-sifat baru dapat diperoleh dengan menggunakan proses high energy ball milling. Ada tiga metode yang secara umum dapat digunakan untuk membedakan kelakuan partikel serbuk selama proses milling, yaitu: mechanical alloying (MA), mechanical milling (MM) dan mechanochemical synthesis (MS). Beberapa keuntungan memproses bahan menjadi nanopartikel dengan menggunakan HEM adalah ukuran beraneka ragam yang bagus, skala besar dan biaya murah. Oleh karena itu proses HEM sangat sesuai untuk memproduksi bahan nanopartikel skala besar.

Makalah ini merupakan studi awal untuk membuat bahan pengisi kapur alam berukuran nanometer dengan menggunakan alat High Energy Milling (HEM). Tujuan penelitian untuk 
adalah mengetahui hubungan antara waktu penggerusan terhadap ukuran partikel karbonat. Penelitian di bidang teknologi nano membutuhkan alat karakterisasi canggih seperti: Transmission Electron Microscope (TEM), Scanning Electron Microscope (SEM), Atomic Force Microscope (AFM), Scanning Tunneling Microscope (STM) dan beberapa fasilitas spektroskopis.

Ketiadaan alat seperti $A F M$ dan kesulitan yang tinggi jika menggunakan TEM tidak berarti akan membatasi penelitian di bidang teknologi nano. Satu cara untuk melakukan karakterisasi struktur nano adalah dengan menggunakan $X$-Ray Difraction $(X R D)$ melalui metode Scherrer. Ukuran partikel nano ditentukan dengan mempelajari pola pelebaran puncak intensitas yang diukur dari data difraksi sinar- $X$ $(X R D)$, dengan menggunakan persamaan Scherrer (Abdullah, 2008).

\section{BAHAN DAN METODE}

\section{Bahan}

Bahan-bahan yang digunakan adalah kapur alam, air demineralisasi, dan etanol. Sedangkan alat-alat yang digunakan adalah High Energy Milling (HEM) seri $8000 \mathrm{M}$ dan XRD merk Phillips PW 2213/20.

\section{Metode}

Kapur alam dihaluskan dengan mortar dan diayak dengan ayakan sampai ukuran 400 mesh. Kapur hasil ayakan dicuci dengan air demineralisasi dan dikeringkan di oven pada $110{ }^{\circ} \mathrm{C}$. Setelah kapur kering kemudian digerus dengan HEM pada variasi waktu milling $3,6,9$, 12, 15 dan 18 jam. Cuplikan diambil pada tiap interval waktu milling dan dikarakterisasi dengan $X R D$.

\section{HASIL DAN PEMBAHASAN}

Hasil karakterisasi kapur alam dengan metode $X R D$ ditunjukkan pada Gambar 1. Pada Gambar 1 ditunjukkan pola difraksi yang diperoleh dari bahan kapur alam yang digunakan pada penelitian ini. Gambar 2 menunjukkan pola difraksi dari $\mathrm{Ca}(\mathrm{OH})_{2}$ standar dari Merck. Sedangkan Gambar 3 mrnunjukkan pola difraksi dari $\mathrm{CaCO}_{3}$ derajat pro analisis yang merupakan standar dari Merck. $\mathrm{Ca}(\mathrm{OH})_{2}$ memiliki nama mineral portlandite adalah termasuk kristal heksagonal. Fasa kristal portlandite ini

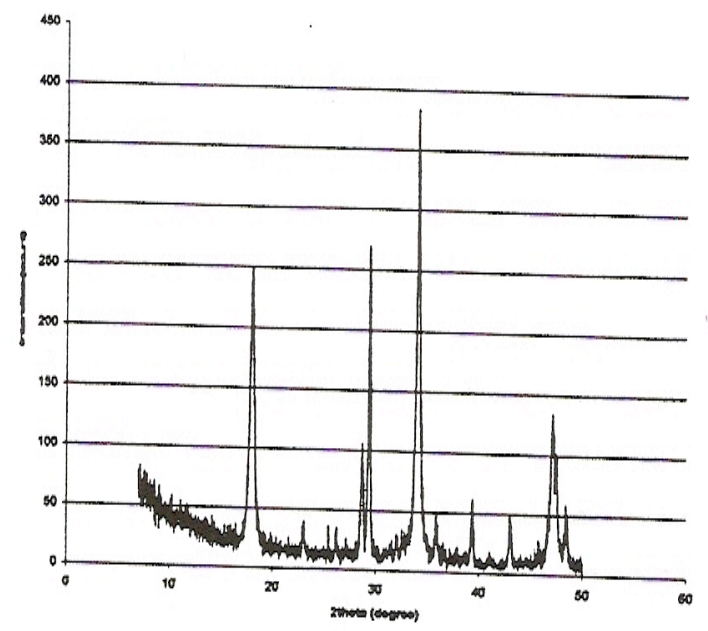

Gambar 1. Pola difraksi yang diperoleh dari bahan kapur alam

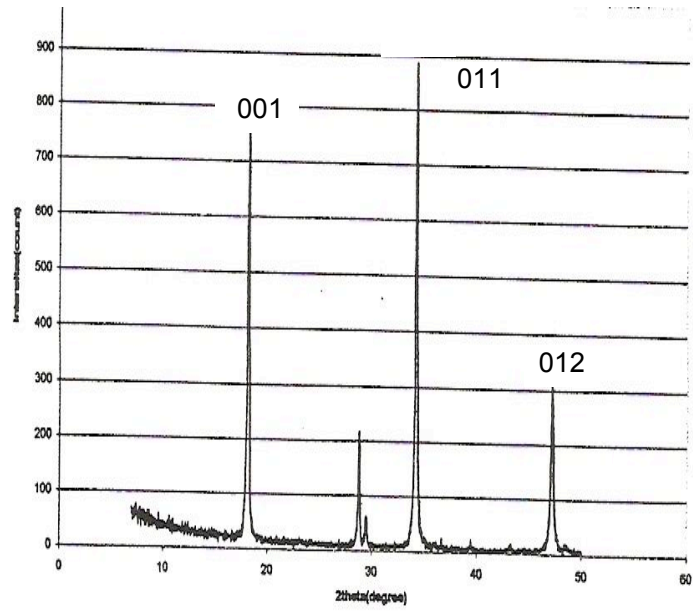

Gambar 2. Pola difraksi $\mathrm{Ca}(\mathrm{OH})_{2}$ standar dari Merck

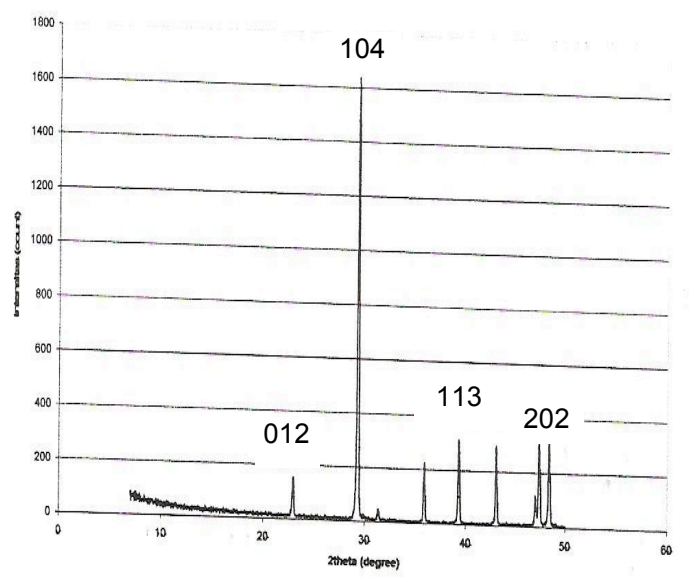

Gambar 3. Pola difraksi $\mathrm{CaCO}_{3}$ derajat pro analisis standar dari Merck 


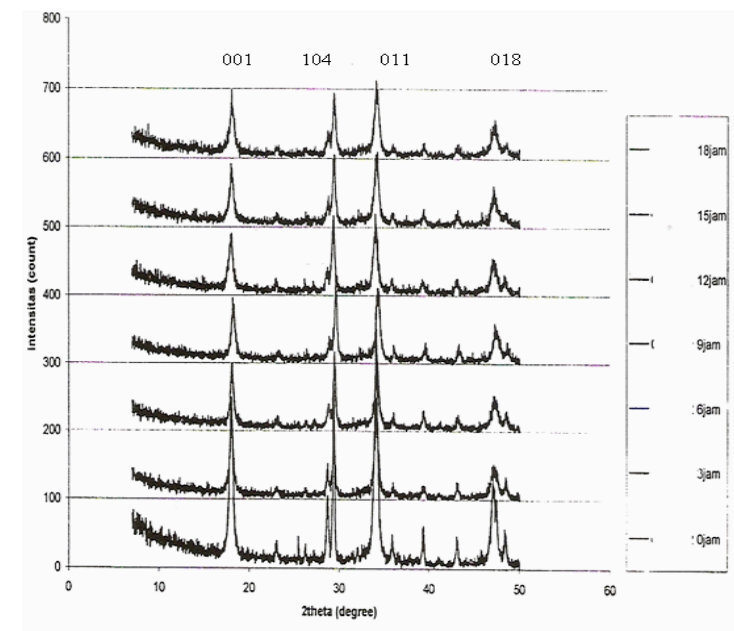

Gambar 4. Pola difraksi dari kapur alam pada variasi waktu milling

ditunjukkan dengan pola difraksi yang tajam dan tinggi pada sudut $2 \theta=34,153 ; 18,073$ dan 47,193 bersesuaian dengan refleksi bidang 011 , 001 dan 012. Sedangkan $\mathrm{CaCO}_{3}$ memiliki nama mineral kalsit berstruktur kristal heksagonal.

Puncak difraksi $\mathrm{CaCO}_{3}$ terlihat pada sudut $2 \theta=29,430 ; 39,398 ; 43,130$ dan 23,052 bersesuaian dengan refleksi bidang 104, 113, 202 dan 012. Pola difraksi kapur alam yang digunakan pada penelitian ini memiliki puncakpuncak pada sudut $2 \theta=18,073 ; 23,052 ; 29,430$; 34,$153 ; 39,398 ; 43,130$ dan 47,193. Puncakpuncak ini adalah milik $\mathrm{Ca}(\mathrm{OH})_{2}$ dan $\mathrm{CaCO}_{3}$, sehingga disimpulkan bahwa kapur alam yang digunakan di penelitian ini adalah gabungan dari kedua senyawa tersebut.

Gambar 4 menunjukkan pola $X R D$ yang dicatat untuk kapur alam sebelum dilakukan proses milling $(0$ jam $)$ dan berturut-turut untuk waktu milling 3 jam, 6 jam, 9 jam, 12 jam, 15 jam dan 18 jam. Gambar 4 juga menunjukkan penurunan intensitas puncak pola $X R D$ dari bahan awal (waktu milling 0 jam). Hal ini menunjukkan bahwa kandungan fase awal tergerus menjadi partikel lebih kecil selama proses waktu milling. Efek pelebaran pola difraksi yang terjadi menunjukkan partikel kapur alam berisikan jumlah besar dari lattice $\mathrm{Ca}(\mathrm{OH})_{2}$ dan $\mathrm{CaCO}_{3}$ akibat penggerusan dengan High Energy Milling. Hal ini dapat juga terjadi karena ukuran partikel semakin mengecil pada waktu milling semakin lama. Metode Scherrer dapat memperkirakan ukuran kristalin selain ukuran partikel. Partikel yang besar terdiri dari banyak kristalin, tetapi partikel nano mungkin hanya terdiri dari satu kristal.
Hasil eksperimen menunjukkan semakin kecil ukuran kristal semakin lebar pola difraksi yang diperoleh. Kristal dengan ukuran besar dan orientasinya tunggal akan menghasilkan puncak yang tinggi dan tajam menyerupai garis.

Sebaliknya kristal yang kecil akan menghasilkan puncak yang melebar, hal ini disebabkan oleh kristal dengan ukuran kecil memiliki jumlah bidang difraksi lebih terbatas. Oleh karena itu pelebaran puncak difraksi dapat memberikan informasi tentang ukuran kristal. Ukuran kristalin ditentukan dengan menggunakan persamaan Scherrer, hasilnya dicatat di Tabel 1 dan Gambar 5. Persamaan Scherrer dapat dituliskan sebagai berikut :

$$
t=K N / B \cos \theta_{B}
$$

dengan, $\mathrm{t}=$ ukuran partikel

$\mathrm{K}=$ konstanta, nilainya $0,87-1$

(biasanya dianggap 1)

$\lambda=$ panjang gelombang sinar $-X$

$\mathrm{B}=\mathrm{FWHM}$ pada $2 \theta$

Tabel 1. Hubungan ukuran kristalin terhadap waktu milling

\begin{tabular}{ccc}
\hline $\begin{array}{c}\text { Waktu } \\
\text { Milling } \\
\text { (jam) }\end{array}$ & $\begin{array}{c}\text { Ukuran Kristalin } \\
\mathrm{Ca}(\mathrm{OH})_{2} \\
(\mathrm{~nm})\end{array}$ & $\begin{array}{c}\text { Ukuran Kristalin } \\
\mathrm{CaCO}_{3} \\
(\mathrm{~nm})\end{array}$ \\
\hline 3 & 1125 & 9000 \\
6 & 1000 & 4500 \\
9 & 562,5 & 1800 \\
12 & 562,5 & 1500 \\
15 & 692,3 & 1500 \\
18 & 473,7 & 600 \\
\hline
\end{tabular}

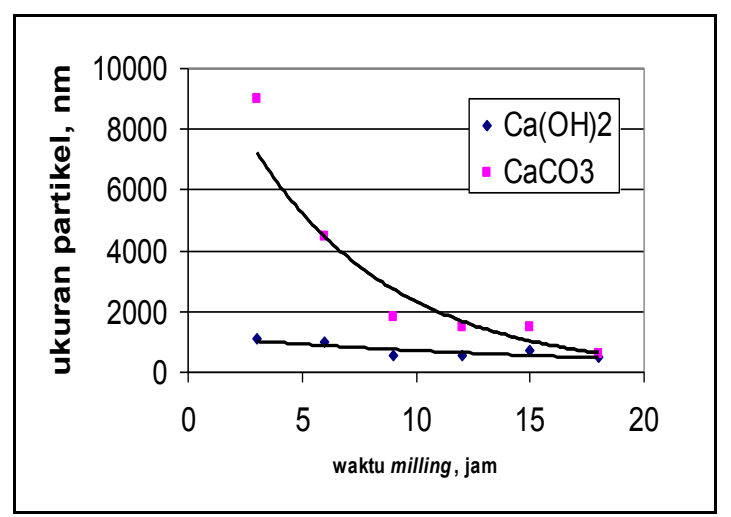

Gambar 5. Pengaruh waktu milling terhadap ukuran partikel $\mathrm{Ca}(\mathrm{OH})_{2}$ dan $\mathrm{CaCO}_{3}$ yang dihitung dengan menggunakan persamaan Scherrer 
Dari Tabel 1 yang kemudian digambarkan dengan Gambar 5 terlihat jelas bahwa ukuran partikel $\mathrm{Ca}(\mathrm{OH})_{2}$ maupun $\mathrm{CaCO}_{3}$ menjadi mengecil dari $1125 \mathrm{~nm}$ pada waktu milling 3 jam menjadi $473,7 \mathrm{~nm}$ pada waktu milling 18 jam untuk $\mathrm{Ca}(\mathrm{OH})_{2}$, atau terjadi penurunan ukuran partikel sebesar $57,9 \%$. Sedangkan untuk partikel $\mathrm{CaCO}_{3}$ pengecilan ukuran partikel terjadi dari $9000 \mathrm{~nm}$ pada waktu milling 3 jam menjadi $600 \mathrm{~nm}$ pada waktu milling $18 \mathrm{jam}$, atau terjadi penurunan ukuran partikel sebesar $93,3 \%$.

\section{KESIMPULAN}

Dari pola difraksi sinar-X disimpulkan bahwa kapur alam terdiri dari senyawa kalsium hidroksida atau $\mathrm{Ca}(\mathrm{OH})_{2}$ dan kalsium karbonat atau $\mathrm{CaCO}_{3}$. Dengan menggunakan persamaan Scherrer dapat dihitung ukuran kristalit penyusun kapur alam tersebut dari pelebaran puncak yang terjadi, menunjukkan bahwa ukuran partikel $\mathrm{Ca}(\mathrm{OH})_{2}$ mengecil dari $1125 \mathrm{~nm}$ pada waktu milling 3 jam menjadi $473,7 \mathrm{~nm}$ pada waktu milling 18 jam, atau terjadi penurunan ukuran partikel sebesar $57,9 \%$. Sedangkan untuk partikel $\mathrm{CaCO}_{3}$ pengecilan ukuran partikel terjadi dari $9000 \mathrm{~nm}$ pada waktu milling 3 jam menjadi $600 \mathrm{~nm}$ pada waktu milling 18 jam, atau terjadi penurunan ukuran partikel sebesar $93,3 \%$.

\section{DAFTAR PUSTAKA}

Abdullah, M. and Khairurrijal. 2008. Derivation of scherrer relation using an approach in basic physic course. J. nano saintek., 1: 28-32.

Chabert, E., M. Bornet, E.B. Lami, J.Y. Cavaille, R. Dendievel, C. Gauthier, J.L. Putaux, and A. Zaoui. 2004. Interaction and viscoelastic behavior of polymer nanocomposites. Mat. Sci. \& Eng. A. 381: 320-330.

Chen, N., C. Wan, and Y. Zhang. 2004. Effect of nano $\mathrm{CaCO}_{3}$ on mechanical properties of PVC and $\mathrm{PVC} / \mathrm{blendex}$ blend. Polym. Test 23: 169-174.

Garcia M., Van Vliet G., Jain S., Schrauwen B.A.G., Sarkissov A., Van Zyl W.E., Boukamp B. 2004. Polypropylene/SiO ${ }_{2}$ Nanocomposites with Improve Mechanical Properties. Rev. Adv. Mater. Sci. $6: 169-175$.

Lorenzo M.I., M.F. Errico, and M. Avella. 2002. Thermal and morphological characterization of poly(ethylene terephtalate) / calcium carbonate nanocomposites. J. Mat. Sci., 37 : 23512358.

Mishra, S. and S.G. Shimpi. 2003. Comparison of nano $\mathrm{CaCO}_{3}$ and fly ash filled with styrene butadiene rubber on mechanical and thermal properties. $J$. Sci. Ind. Res. 64 : 744-751.

Wan C.X., Qiao, Zhang Y. 2003. Effect of epoxy resin on morphology and physical properties of PVC/organophylic montmorillonite composites. J. Appl. Polym. Sci. 89: 2164-2191.

Wang Y.Q., Y.P. Wu, H.F. Zhang, L.Q. Zhang, B. Wang, and Z.F. Wang. 2004. Free volume of montmorillonite/styrene butadiene rubber nanocomposites estimated by positron annihilation lifetime spectroscopy, Macromol. Rapid Commun. 25: 1973-1978. 